\title{
Inequality Dynamics in Malta: Cracks, Blips and Long-Term Trends
}

\author{
Melchior Vella $^{1,2}$ \& Gilmour Camilleri ${ }^{1,2}$ \\ ${ }^{1}$ Centre for Labour Studies, University of Malta, Malta \\ ${ }^{2}$ Department of Economics, University of Malta, Malta \\ Correspondence: Melchior Vella, Centre for Labour Studies, University of Malta, Malta. E-mail: \\ mvell31@um.edu.mt
}

Received: August 18, 2021

Accepted: September 14, 2021

Online Published: September 24, 2021

doi:10.5539/ijef.v13n11p1

URL: https://doi.org/10.5539/ijef.v13n11p1

\begin{abstract}
This study analyses changes in income inequality in Malta and its driving factors between 2005 and 2018. The study employs and analyses data collected by Malta's National Statistics Office, which conforms with the European Union Survey on Income and Living Conditions. Education and labour status are identified as key drivers behind income inequality changes over the period under review. While the Gini coefficient remained relatively stable between 2005 and 2018, the Lorenz curve moved further away from the line of equality at the upper end of the income distribution, showing modest increases. Over the 2014-2018 period, Government intervention has been mildly neutralizing through social transfers but not through taxes. Social transfers provided a greater safety net to citizens than they did during the 2005-2009 period, whereas tax reforms have abraded some tax progressivity. We also find that inequality was mostly attributed to differences in the individual's qualifications, hours worked, occupations, and household employment structure and size, highlighting an important role for policy to further reduce the barriers to economic inclusion.
\end{abstract}

Keywords: income inequality, economic growth, Malta

\section{Introduction}

The fundamental theorem of welfare economics provides little guidance in analysing problems of inequality. The concentration is on efficient outcomes and avoids all together value judgements about the distribution of resources. A situation is optimal if someone can be made better off without making someone else worse off. In this respect, optimality guarantees that no change is possible without worsening someone else's outcome despite disparities that might exist between richer and poorer individuals.

Besides unfairness, inequality reflects the wastefulness of resources. More precisely, the latter describes the costs of inequality associated with insurmountable unequal life chances irrespective of individual effort. Thus, assuming that more is preferred to less without heeding the distribution of resources is nonsensical. In this respect, strides were made in the literature beyond the narrow definition of Pareto optimality and recognised distributional judgements and welfare comparisons.

The second characteristic particular to this debate concerns the perspective one should employ when assessing income inequality across a population. Although standard statistical concepts serve as common ground to measure inequality and poverty, there are no agreed-upon definitions. In practice, there are multiple perspectives in economics discussions. One commonly used concept of inequality is the variance, with a broader dispersion of distribution around the mean associated with higher variance. Though important, the variance misses relevant information. Two immediately following-up questions are: what are the representative values (mean, median, mode), and the shape of the distribution (skewness and kurtosis)? All concepts are perfectly valid. The challenge is to identify all features of income distribution and find the most critical factors contributing to the levels and changes in inequality.

Another important issue to this debate concerns the sensitivity towards inequality among the poor and the rich. Metrics contain an element of attitudes towards inequality aversion. This parameter is required to rank income distributions according to inequality and assess the effects of social transfers and taxes on income inequality and poverty. However, there are no default parameter values. This brings up the debate about whether inequality measures should be more sensitive to what happens in the upper- or bottom-tail of the distribution or perhaps more sensitive to income differences around the middle. 
Besides, there is always an element of judgement when interpreting these commonly used indices. Some consider inequality a "bad" thing, but others value inequality as a reward for education, hard work, and ability. It is difficult to think of judgements as "correct" or "incorrect". For this reason, inequality could easily be thought of as a closed box. It is unclear to many what inequality is, yet understand its evolution and interlinkage with factors that drive it (Jenkins, 1995; Brewer et al., 2009).

The diagnosis of the factors that caused the trends in income inequality and their relative importance remains largely contested, particularly with respect to forces such as the roles of globalisation versus technology and market forces versus institutions and policy choices (Nolan et al., 2019). Another complexity is that studies focus on different periods and use a range of definitions and datasets, out of which no comparable conclusions can be made. Furthermore, in terms of the methodology employed, there are analytical and shift-share methods that identify the factors and the extent to which they have contributed to income inequality. Arguably, the shift-share approach resembles more the counterfactual experiment than the arithmetic decomposition. However, in the former case, assesing the effect of a large number of influences becomes complex to handle and does not provide an exact decomposition (Jenkins, 1995).

This study analyses development in inequality in Malta between 2005 and 2018, presenting a refined analysis distinguished from the vernacular. We recognise that measurement and value judgement issues have plagued the debates with repetitious statements, either of frustration or fatigue, with outlandish claims that "inequality is rising" or conversely that "inequality is falling". The approach is motivated by the desire to relate indices explicitly to inequality factors without passing value judgements.

This research is motivated by the dearth of information about which factors have contributed to these changes and their relative importance, a knowledge gap in the area for Malta. In doing so, we look into which sources of income and fiscal instruments have contributed to inequality changes over the past thirteen years.

This study demonstrated that in isolation, an income inequality indicator hides the complexity of the income distribution. The current analysis identified several factors affecting income inequality, including education, labour market status, and occupation. On the other hand, the welfare system appears to limit or reduces inequality.

Following this introduction, Section 2 presents an overview of the different income inequality measures. This is followed by outlining the data and the methodology adopted for this study in Section 3. Section 4 presents the main findings of income inequality in Malta between 2005 and 2018. Section 5 concludes.

\section{Measuring and Understanding Income Inequality}

Measuring income inequality is not straightforward, partly because inequality has various connotations, and measures are explicitly linked to value judgements. There is no logical argument for comparing a uniform to unequal income distribution from the fundamental theorem of welfare economics. This section aims to present the link between the inequality measures and the income distribution evaluation involving value judgments.

\subsection{Properties of Inequality Indices}

A measure of inequality is an index, which measures the distribution's degree of dispersion. There are many properties that an index must satisfy (Shorrocks, 1980; Cowell, 2000; Jenkins \& Van Kerm, 2011). One of the desirable properties of an index is 'scale invariance'. Scale invariance is considered necessary because irrespective of the units of measurement, inequality should remain unchanged. Scale invariance could be imposed by generating the variance of the logs ('translation invariant'). Translation invariance requires the inequality index to be invariant to uniform additions or subtractions to original incomes. Another property is 'replication invariance', which states that the simple replication of individuals and income should not alter the inequality index. In other words, an index is invariant if it is only sensitive to the individuals' relative position and not to the number of individuals. Another property is 'symmetry' or 'anonymity'. This axiom says that the index should only depend on the income values used to construct it. Thus, when measuring inequality, it is ensured that no other relevant information is ignored. A way how to adjust income for household size and structure and at the same time reflect the household characteristics and anonymity is through equivalisation. The final property is the 'principle of transfers': transfers from rich to poor individuals must be accompanied by reductions in the inequality index. This notion was extended by Shorrocks and Foster (1987) into 'transfer sensitive' property, which states that a given transfer has a more considerable impact amongst poorer than more affluent households. The basic idea is that inequality among the poor reduces welfare by more than inequality among the rich. 


\subsection{Common Measures of Inequality}

There are several methods of how income inequality can be measured. In general, the measures take two forms, either graphical or analytical.

The coefficient of variation (CV) is a common measure of variability. $\mathrm{CV}$ expresses the standard deviation as a ratio to average income. Unlike the variance, CV is scale-invariant, satisfies the principle of transfers, but it is not translation invariant. Because the variance is scale variant, a way around it is to take the variance of log values. The logarithmic transformation tends to reduce the deviation, and makes it more sensitive to inequality at lower income levels whilst contracting income differences at higher income levels. Like the variance and CV, the variance of logs takes differences only from the mean and square it, which is a limitation. Because it becomes so insensitive to inequality amongst the rich, it violates the principle of transfers. Therefore, inequality can increase even in the presence of rich-to-poor transfers at high-income levels (Dasgupta, Sen, \& Starrett, 1973).

The most common index of inequality is the Gini coefficient attributed to Gini (1912) and much analysed by Ricci (1916) and later by Dalton (1920), Yntema (1938), Atkinson (1970a), Newbery (1970), Sheshinski (1972), and others. The Gini has derived from the Lorenz (1905) curve framework. The Lorenz curve is composed of data points showing the cumulative proportion of income earned by the cumulative percentage of individuals. The curve would be a straight line for perfect equality, and it becomes more curved as inequality rises.

The Gini coefficient represents the Lorenz curve because it is equivalent to the size of the area between the Lorenz curve and the line of income equality expressed as a proportion of the total area under the linear line. Therefore, the Gini can take any value between 0 and 100, with a value of 0 reflecting pure equality, whereas a value of 100 reflecting pure inequality with the total income enjoyed by only one individual. An appeal of the Gini coefficient is that it avoids arbitrary squaring, and it directly measures inequality between every pair of incomes rather than deviations from the mean. In fact, another interpretation of the Gini coefficient provided by Sen and Foster (1997) is as follows:

$$
G=\left(\frac{1}{2 n^{2} \mu}\right) \sum_{i=1}^{n} \sum_{j=1}^{n}\left|y_{i}-y_{j}\right|
$$

where $y$ is the income of person $i, \mu$ is the average level of income, $n$ is the size of the population, so that $\left|y_{i}-y_{j}\right|$ is the absolute values of differences between all pairs of income.

With individuals labelled in non-descending order of income, the Gini is simplified to:

$$
G=1+\left(\frac{1}{n}\right)-\left(\frac{2}{n^{2} \mu}\right)\left[y_{1}+2 y_{2}+\cdots+n y_{n}\right] \text { for } y_{1} \geq y_{2} \geq \cdots y_{n}
$$

As is clear from Equation (2), the Gini coefficient's limitation is that transfers from richer to poorer persons are captured by the index if and only if it changes the ranks in the distribution. In other words, the Gini coefficient does not depend on how poor the poorer person is but on the number of people between income brackets. This caveat limits comparisons over time and across countries and may even confound income inequality tests. Furthermore, the Gini coefficient is more sensitive to changes in income in the middle part or mode of the distribution (Hey and Lambert, 1980) and does not satisfy a strictly concave welfare function (Shorrocks \& Foster, 1987). Because of this sensitivity, the Gini is not "value-free", and assessing inequality necessitates complementing the Gini with other indices.

\subsection{Complementary Measures of Inequality}

Many other inequality indices were developed, with desirable characteristics not necessarily satisfied by the standard indices. Three other inequality indices are the Theil index, the mean logarithmic deviation, and half the squared coefficient of variation. All three indicators are members of the Generalised Entropy (GE) class (Cowell and Kuga, 1981). The formula for general entropy for a given value of $\alpha$ is:

$$
G E(\alpha)=\left\{\begin{array}{c}
\frac{1}{n \alpha(\alpha-1)} \sum_{i-1}^{n}\left[\left(\frac{y_{i}}{\bar{y}}\right)^{\alpha}-1\right], \alpha \neq 0,1, \\
\frac{1}{n} \sum_{i=1}^{n} \frac{y_{i}}{\bar{y}}, \alpha=1, \\
-\frac{1}{n} \sum_{i=1}^{n} \ln \frac{y_{i}}{\bar{y}}, \alpha=0 .
\end{array}\right.
$$

where $\alpha$ is a parameter measuring the sensitivity of inequality along with the different parts of the income distribution. The larger $\alpha$ is, the more sensitive the index is to the existence of large incomes. Conversely, the smaller $\alpha$ is, the more sensitive the index is to the existence of small incomes. The GE measures respect most of 
the desirable properties discussed above (Cowell, 2000). Another important characteristic of GE is that it can be decomposed into between- and within-group and by population subgroups.

\subsection{Connection Between Distributional Properties and the Lorenz Ordering}

To better understand the link between the distribution of income and the Lorenz Curve, we illustrate changes in the four moments of a distribution. We consider four scenarios: translation/location shift, scale shift, right-skewed shift and left-skewed shift (Hao \& Naiman, 2011). First, location shift results from adding or subtracting a fixed amount to every member of the population. Second, scale shift results from increasing or decreasing everyone's income by a fixed percentage. A skewed shift is a result of increasing or decreasing the income of the population by different amounts.

The effect of a positive location shift, which is raising every member of the population by the same amount, raises the Lorenz curve above the original curve, thereby reducing income inequality. Intuitively, a fixed absolute increase in income increases the income of the poor proportionately more than the rich.

The Lorenz Curve is invariant to scale shift as its mean normalises it. A positive location-scale shift increases both the mean and the standard deviation; however, leaving the skewness and the kurtosis unchanged.

Furthermore, the Lorenz Curve captures skewed shifts in the distribution. If the rich become richer (left-skewed shift), it moves the Lorenz Curve down the original. If the rich are taxed more than the poor, the Lorenz Curve moves closer to the equality line.

Besides providing a descriptive representation of inequality, comparing Lorenz curves of two or more years assesses whether inequality is higher or lower than the previous year. Suppose the Lorenz curves of two distributions do not cross, and one strictly lies inside that of another. In that case, one can conclude that inequality is smaller in distribution. It does not matter which inequality index is employed as long as it respects the properties of scale invariance, replication invariance, symmetry, and the principle of transfers (Foster, 1985).

However, no hard and fast conclusions can be made whenever Lorenz curves intersect unless further restrictions on the inequality measure are imposed. For example, if the Lorenz curve in the base year intersects the curve of the following year from above, and if the CV of the base year is at least less than or equal to the CV of the following year, then inequality is lower in the base year for any transfer-sensitive inequality measure (Dardanoni and Lambert, 1988; Davies and Hoy, 1995; Shorrocks and Foster, 1987).

\subsection{Factors Affecting Inequality}

\subsubsection{Education}

The human capital theory postulates that education increases income. Therefore, in theory, educational expansion decreases income inequality and increases intergenerational mobility. However, empirical evidence shows that educational expansion augments income gaps from returns on higher education rather than compulsory education. There is also evidence showing that pay gaps are still likely to persist as more people acquire higher education. Therefore, promoting higher education on its own is unlikely to reduce income inequality significantly.

There are various reasons why higher education comes with better pay. By acquiring education credentials, workers signal their ability and skill level to the employer (Hendel et al., 2005). In other words, if all individuals can afford to go to university, then only low-ability individuals will not participate in higher education. Because those who do not graduate will not indicate their high levels of abilities, employers will reward skilled workers and penalise non-graduates with lower pay. Hence, education creates a wage gap between those who graduated with higher education and those without higher education. Indeed, using a cross-section of countries, Sylwester (2002) found that devoting more resources to education through public expenditure can positively affect income distribution.

While the educational gap between wealthy and poor children is one of the most evident manifestations of income inequality, the difference in income often comes down to differences in ability. For example, Checchi et al. (1999) found that family background is important for success in the labour market. In another study, Restuccia and Urrutia (2004) found that parents' early educational investment could explain approximately 50\% of intergenerational mobility, and income inequality was mainly due to higher education. Hence, a centralised and egalitarian tertiary education may not necessarily help children from low-income households compete with rich children in a world where family background is important for success in labour market. In the same vein, 

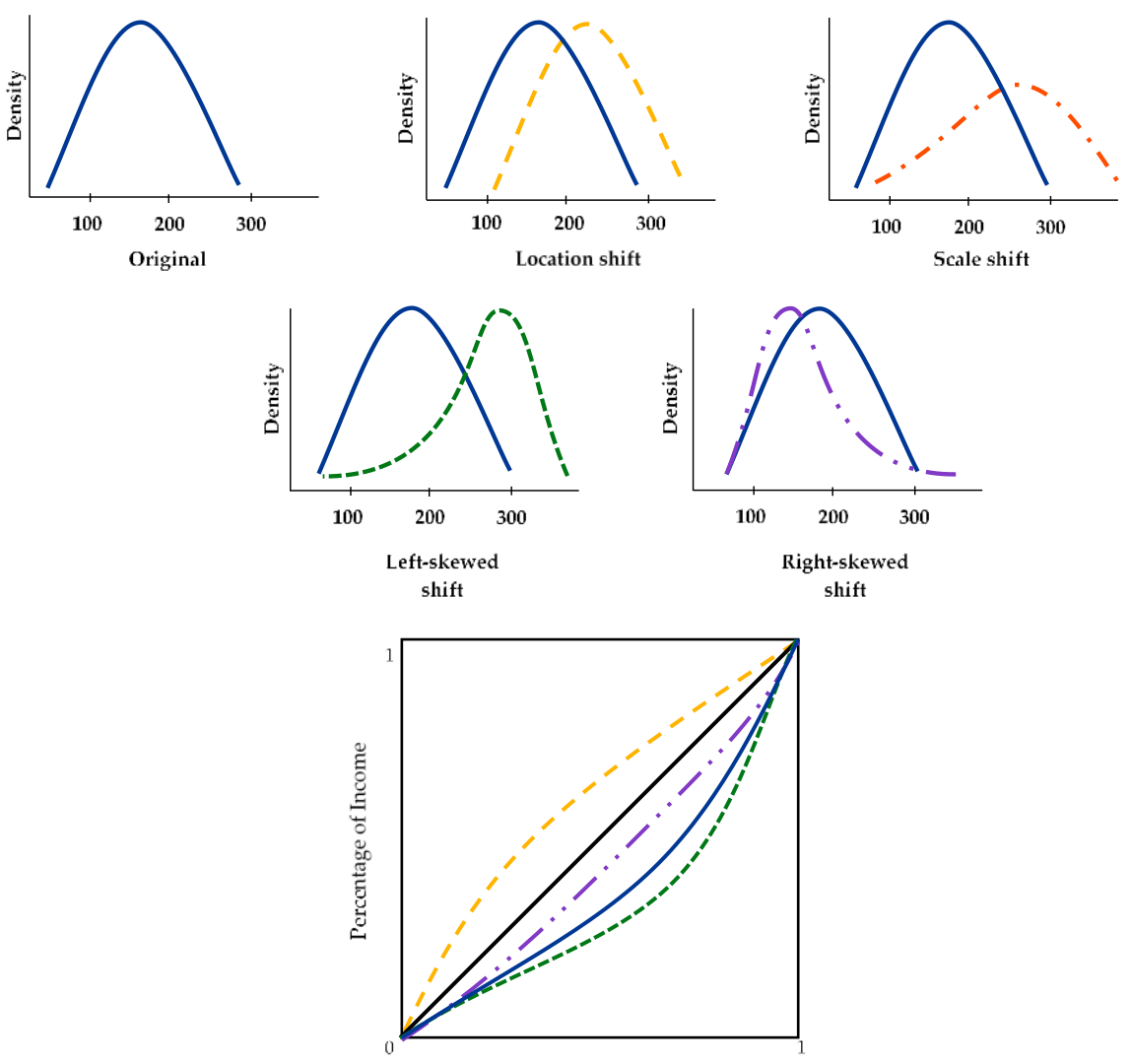

Percentage of Population

$$
\text { Location Shift } \quad \text { Scale shift } \quad \text { Right-skewed shift } \quad \text { Left-skewed shift }
$$

Figure 1. Hypothetical distribution of income and its four shifted distributions

Yang and Qiu (2016) show that though children from the wealthiest families are slightly smarter than those from the poorest, the gap in human capital almost doubles at the end of non-compulsory education. Such findings demonstrate that the effect of education can be meddled by other characteristics, such as family background and social status. Poorer families invest relatively less in children's early education than wealthy families; therefore, they attend lower-quality schools, making them less likely to participate in higher education.

It is important to note that the mechanism in forming income inequality is implausible to be formed only by education. Education could affect income inequality by other means, such as occupation, marriage matching, health, access to finance, parental investment, and the number of children in the household. Other mechanisms are also likely to affect education and indirectly inequality. For example, parents' nutrition will affect children's health, further affecting their educational achievement and labour productivity.

\subsubsection{Occupation and Skills}

Another important driver of inequality is occupational choice. An occupation can be considered the aggregation of different jobs reflecting the heterogeneous duties, tasks, and skills required and mirror social stratification. Previous empirical literature shows that between-occupation inequality has risen faster than within-occupation inequality, reflecting an increase in its relevant importance (Autor et al., 2006; Mouw \& Kalleberg, 2010; Weeden et al., 2007).

Using a simple labour demand and supply analysis, some jobs such as doctors and medical practitioners are difficult to substitute by any graduate without first completing a specialised and long duration form of training. Because an increase in demand for highly skilled occupations cannot be easily matched with a corresponding increase in supply, this results in pay differences between various occupations, particularly between skilled-based and routine-based occupations. Another reason for the differences in pay between jobs could be compensating differentials. The additional income arises because of unpleasantness, risk, or other undesirable attributes of a particular job. Typically, compensating wage differential provides a special benefit, but this 
differential would be negative; that is, a worker would be willing to accept lower income for a nearly desirable job relative to other jobs.

The ultimate effect on inequality is unclear. The relative higher wages lure new entrants to those professions and eat away some of the occupational premia in the longer term. Furthermore, the differences in pay could be explained in the context of other factors, such as globalisation, technology advancement, market power in the product and labour market, and labour market institutions and policies. Increased trade can intensify occupational switching leading to real wage reductions, a polarised labour market, and more wage inequality.

New technologies tend to penalise low-skilled and routine-based occupations and favour other particular groups of the workforce. In particular, low-skilled and blue-collar workers have already borne a considerable share of adjustment costs of innovation. Moreover, there is evidence that inequality between elementary occupations and professions has widened in European countries, pointing to the skill-biased technological change witnessed in recent decades (Goos et al., 2009).

Moreover, while technological change has proved the ease of substituting unskilled labour with capital, recent developments raise alarms for adverse consequences on employment from the widespread use of new ICTs, including machine learning, digitalisation of production, robotics and automated vehicles. While we do not want to underestimate the job-creating potential of fundamental technological transformations, there is a lack of awareness about the permanent changes that technology has on the labour market. By way of example, authorities' restrictions following the coronavirus outbreak have shown that workers in the services industry are not immune to technology change. New technologies are increasingly substituting routine tasks in white-collar and administrative ones. Individual tasks have become increasingly tradeable over the internet and self-employed working on a project-by-project basis increased. Such a 'platform' or 'gig' economy may lead to more self-determination and a better work-life balance for employees. However, it could also lead to job insecurity, precarious employment and periods of involuntary unemployment.

Though the effects on inequality are likely to be modest for the developed countries, labour markets have become characterised by dichotomous developments across occupations in terms of benefits and costs of greater globalisation (Nolan et al., 2019). An example is a fall in employment for middle-skill intensive occupations and a rise in low-skill and high-skill occupations for many advanced countries (Goos et al., 2014). Moreover, technological advancement is also linked with job polarisation and ease of offshoring specific job tasks, potentially leaving scarring effects on wages of certain occupations, hence inequality.

Related to this is trade unionism. The fast-changing landscape of the labour market rattled trade unionism and led to individualism amongst workers (Baldacchino, 1993; Zammit, 1993). Members used to unite and redefine power collectively; however, globalisation, technological change and job polarisation rendered this problematic. Such division also led various sectors in Malta to be union-free. Baldacchino (2010) identifies real estate, small businesses, construction, retail, and catering as the most cited examples. Whilst in Malta, the public sector remains almost fully unionised, the percentage of workers covered by a collective agreement in the private sector followed a downward trend in recent years (Baldacchino \& Gatt, 2009). Undoubtedly, regulation and control promote employees' interests and foster employees' confidence to negotiate and bargain their conditions. However, workers in precarious and gig industries tend to remain exploited and generally do not seek to promote their interests by collective representation efforts, possibly due to the fear of losing more if they clash with their employer.

Because we do not have data on collective bargaining, we attempt to explain inequality develpoments by occupations. Nevertheless, the net effect of inequality is perplexed because of the high heterogeneity in industries, sectors and work conditions.

\subsubsection{Household Structure and Employment}

Household structures are changing in Malta, with implications on the form and extent of inequality. Changes in household structures have a bearing on the distribution of income in a society. It follows that because parenthood starts at a later average age, the number of households with no children is on the rise, marriages are less stable, and the proportion of individuals who are separating/divorcing, living on their own or cohabitating are becoming more common.

The overall effect of changing living arrangements on inequality is complex to decipher and depends on a range of micro and macro factors. For example, while increased female employment is expected to reduce income inequality, the increased prevalence of single-mother families heightens income inequality (Kollmeyer, 2013). For households with two or more adults, growth in female participation creates new opportunities to pool 
incomes and reduce financial risks. On the other hand, single-parent households face entrenched barriers to maintaining income parity with other households.

The total effect of dual or multi-earner households on inequality remains disputed. Although stronger attachment to the labour market should reduce income inequality at face value, evidence portrays a different experience. Indeed, income inequality in most Western countries was lower when most families adhered to the male breadwinner model. The father worked full-time outside the home, and the mother engaged in unpaid domestic work (Lewis, 1992). However, this family model slowly became less prominent as more women opted to join the labour market and income inequality increased (Schwartz, 2010). A factor explaining this paradox is homogamous marriages. Partners tend to resemble one another in terms of their qualifications, class backgrounds, and career accomplishments. This characteristic intensifies income inequality by combining two high-income earners or two low-income earners into separate households. Such development does not mean that the socioeconomic advantages and disadvantages were not present in low female participation rates. Still, merely they were being realised once female employment started to increase incrementally.

Related to the household structure is the employment status of the head of the household. One would expect between-employment status inequality to rise faster than within-employment status inequality because work and unemployment have a cyclical aspect, and divergences between the two may become more pronounced in times of high economic growth. Furthermore, low-skilled workers are likely to join the ranks of employment in greater numbers in economic booms and are more susceptible to unemployment during economic downturns.

Besides the household's employment status, household income and inequality are also affected by the number of other individuals in employment in the household. Households with zero work intensity are likely to have significantly lower incomes than households with higher work intensity.

\subsubsection{Ageing Population}

Like other developed countries, Malta's population is ageing rapidly, primarily because of decreased fertility and increases in longevity. The likely possibility is a generational imbalance, with the young cohort unlikely to be better off than those already retired (Vella \& von Brockdorff, 2019). This is, however, conditional on the ability to sustain wage growth in the long term. The debate on the effect of a higher dependency ratio on wages is still open and inconclusive. Jenkins (1995) postulated that a population with a higher relative number of elderlies could change relative wages and widen income differentials between the old and the young workers.

\section{Data and Methodology}

We investigate income inequality using cross-sectional data for the years 2005 to 2018 . The data were sourced from the EU-SILC datasets provided by the National Statistics Office of Malta.

We follow Eurostat's definition of equivalised disposable income (household disposable income divided by the equivalent household size). Household disposable income comprises all monetary incomes received from any source by each household member, including income from work, investment and social benefits, and any other household income. Taxes and social contributions paid are deducted from this sum. The equivalent household size is calculated according to the "modified OECD" equivalence scale, that is a weight of 1.0 is assigned to the first adult, a weight of 0.5 is assigned to the second and each subsequent person aged 14 and over, and a weight of 0.3 to each child aged under 14 . The equivalence adjustments reflect differences in household's size and composition.

Inequality measures are calculated both for equivalised disposable income and for each income component (over households) and earnings (over individuals). Notably, the assessment of inequality at the individual level leaves aside observations with non-positive earnings. In this respect, inequality calculations at the individual level should be interpreted within this context, as otherwise, this would create considerable bias in the analysis.

We describe income inequality using the Lorenz curve, the Gini coefficient, the mean logarithmic deviation (i.e., generalised entropy measure with $\alpha=0$ ), the Theil index (i.e., generalised entropy measure with $\alpha=1$ ), and half the squared coefficient of variation (i.e., generalised entropy measure with $\alpha=2$ ).

Following the discussion on inequality measures in Section 2, we assess which factors or subgroups of the population shape inequality and how important they are. In this analysis, by using the standard between and within decomposition methods, we determined whether changes in income inequality were driven mainly by differences between groups or heterogeneities within them. We also break down inequality by income source to provide an insight into which streams of income drive inequality (Note 1). Decomposing inequality helps us to explain the aggregate measure and its changes over time. 


\section{Results}

\subsection{Lorenz Curves}

The Lorenz Curve shows that in 2018, the bottom $40 \%$ of the population earned $22 \%$ of the total income while the bottom $80 \%$ of the population got $63 \%$ of total income (Figure 2a). This implies that the remaining $37 \%$ of income went to the richest $20 \%$ of Malta's population. In general, there were no substantial changes in the Lorenz curves over the past fourteen years. However, there were marginal increases in total income inequality at the upper end of the distribution. Had there been major increases in inequality, we would have seen the curve becoming more sag below the line of perfect equality. Despite the stable performance, there were slight increases in total income inequality at the upper end of the distribution.

By contrasting the Lorenz curves across years, we can evaluate if inequality in a particular year dominates inequality to its prior wave. As is evident, between 2005 and 2009, inequality was less prevalent among households earning $20 \%$ of total income. This contrasts with post-financial crisis periods characterised by small magnitude Lorenz dominance, showing increasing inequality across all income groups. Furthermore, the cumulative Lorenz curve difference is negative for almost all income groups, meaning that the income distribution has become less equal between 2005 and 2018 (Figure 2b). The chart allows us to conclude that most of the changes in income distribution were driven by changes in the top $90 \%$ of the distribution.

It is also interesting to plot how the different income components across population rank (Figure 3a). Because the picture remains more or less the same, only the curves for 2018 are shown. As expected, the concentration curve of transfers lies above the equal distribution line, meaning that transfers benefit households with low earnings. For example, the bottom 50\% of households receive about $62 \%$ of all transfers. However, earnings and other income sources are skewed towards high earning households. Indeed, the bottom $50 \%$ of the population receive about $21 \%$ of all earnings and $23 \%$ of all other income. Because the tax concentration curve lies below the equal distribution line, confirming having a progressive income tax system. In fact, the bottom $50 \%$ of the population contribute to $18 \%$ of total taxes collected from households.

Figure $3 \mathrm{~b}$ shows the cumulative changes for each income source between 2005 and 2018 plotted against the share of the population. A positive change at a particular point in the distribution means that the bottom proportion of households in the income distribution has more of that income source, reflecting a redistributive effect from the rich to the poor. On the contrary, a negative change implies that the share of an income component earned by the bottom proportion of households decreased, reflecting higher income inequality for that income cohort.

Over the fourteen years, transfers constituted a smaller share for the bottom $20 \%$ of households in income, whereas transfers for middle-income households faired positively. Meanwhile, earnings and other income components became more skewed towards high-income households. Taxes on income retained their progressive nature; however, the tax curve does not dominate the earnings curve for the top 50\% richest households. This suggests a loss in their redistributive power, though it is of minimal magnitude.

\subsection{Inequality Indicies}

Inequality measures are computed using the Modified-OECD equivalence scale, which is the definition adopted by Eurostat. The results are presented in Figure 4, showing four measures of inequality, all indexed to be equal to 100 in 2005 .

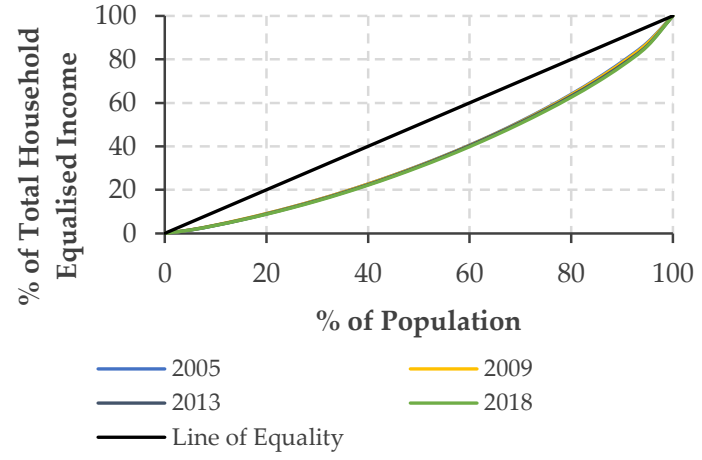

Figure 2a. Lorenz Curves

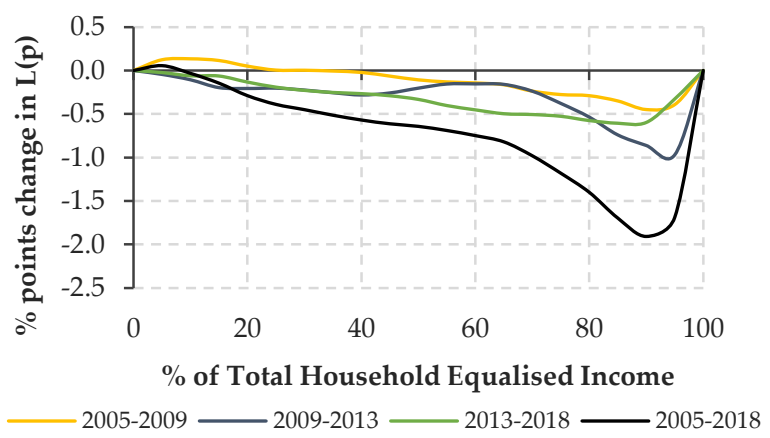

Figure 2b. Cumulative changes in Lorenz Curves

Note. EU-SILC, Authors' Calculations. 
Between 2005 and 2018, the Gini coefficient has increased by $6 \%$ from 27.0 to 28.7 . The dynamics in the Gini contrasts with $\mathrm{GE}(2)$, which, when weighing emphasis on higher ends of the distribution, shows a stark increase of $23 \%$ over the 14 years. In addition, the mean logarithmic deviation (GE1) and the Theil (GE0) index demonstrate an increase of $16 \%$ and $10 \%$, respectively.

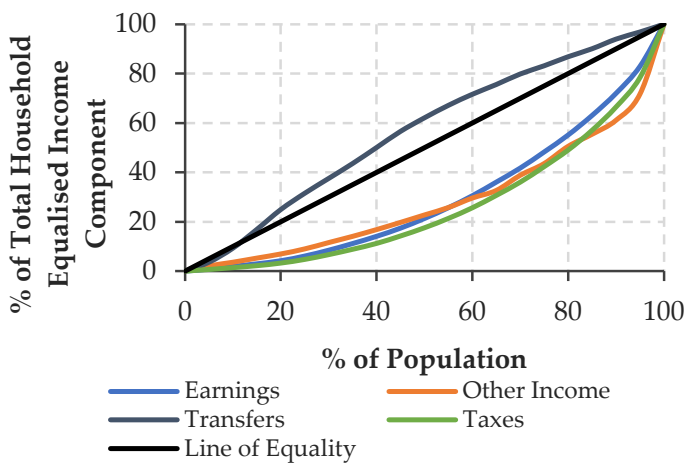

Figure 3a. Concentration curve, 2018

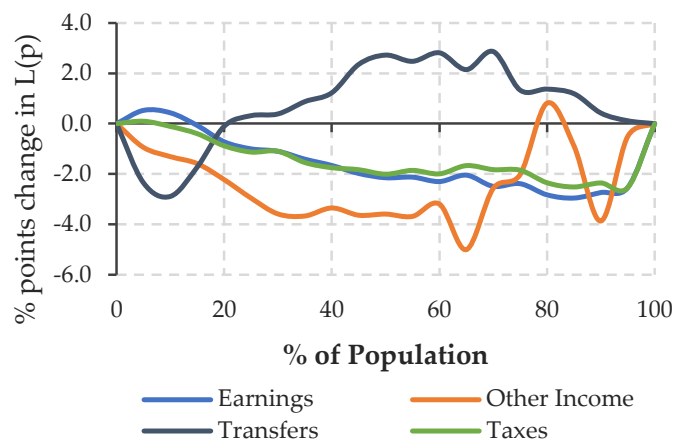

Figure 3b. Change in shares, 2018 over 2005

Note. EU-SILC, Authors' Calculations.

All inequality measures appear to be showing an upward trend. However, neither measure has increased steadily, with increases in inequality largely reversed in the subsequent year. Moreover, not all measures have increased at the same pace. Though the dynamics of the GE indicators are somewhat similar, the scale of changes is more pronounced at the upper end of the distribution. This is different from the Gini coefficient, which demonstrates the most stable pattern and is sensitive to income differences around the middle part of the distribution.

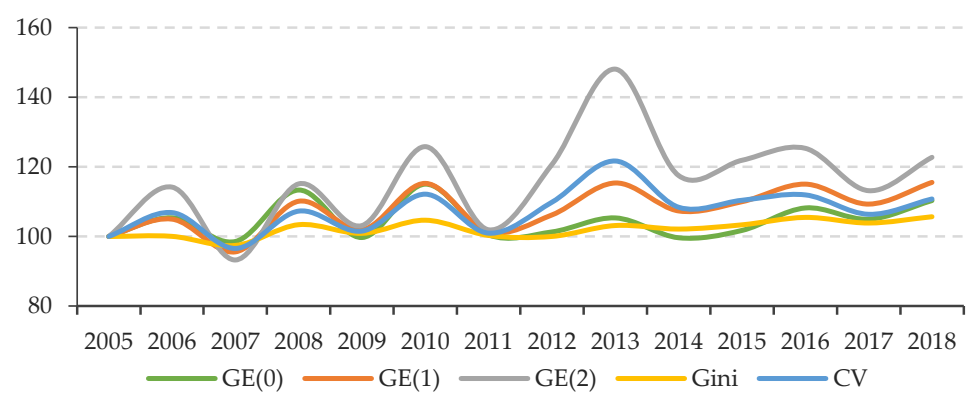

Figure 4. National equivalised household income inequality index, 2005-2018

Note. EU-SILC, Authors' Calculations.

From these inequality measures, we can identify three periods that deserve separate designate. Between 2005 and 2009 , inequality remained on average stable, coinciding with periods of steady income dynamics. Save for 2011, between the years 2010-2013, all inequality measures have ticked upwards following the economic recession in 2009, particularly because of inequality at the upper tail of the distribution. Another interesting development is that the divergence between inequality measures became more explicit and remained so between 2014 and 2018 .

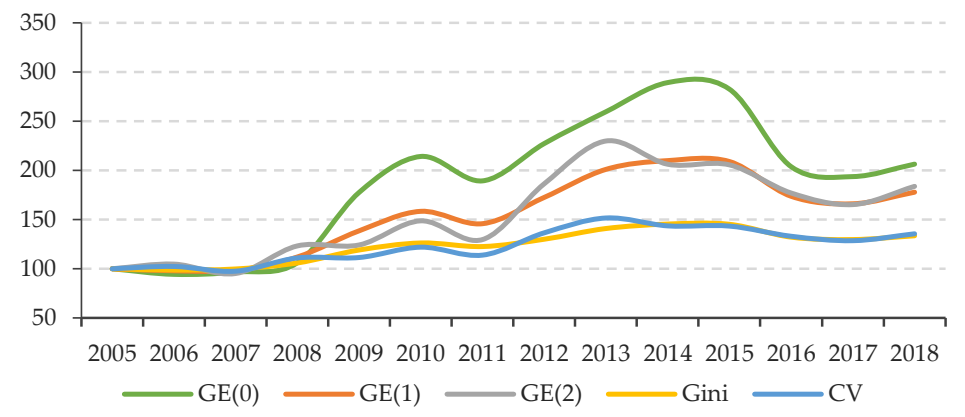

Figure 5. Earnings inequality index at the individual level, 2005-2018 
Results for earnings inequality show a contrasting picture (Figure 5). First, the Gini coefficient for earnings is much higher than for the household equivalised disposable income. This shows that household size and composition, social transfers and taxes play an important role in the final inequality metrics. Second, while GE(2) is again the indicator with the highest score across all generalised entropy indicators, $\operatorname{GE}(0)$ is greater than $\operatorname{GE}(1)$, meaning that inequality is more pronounced at the bottom of the earnings distribution.

In terms of relative changes, the divergence arises from 2008. In general, this suggests that inequality at the bottom of the earnings distribution increased strongly after 2008, then fell in 2016 and remained stable after that. Again, the Gini coefficient demonstrated the lowest pronounced increases in inequality, suggesting that the rise in inequalities was less experienced in the middle of the earnings distribution.

A comparison of different entropy measures indicates that much of the changes took place in the upper and bottom tail of the distribution, both for disposable income at the household level and earnings at the individual level. Increases in inequality in the middle part of the distribution are relatively small. It can be argued that transitional processes characterise the increase in inequality in certain parts of society in household composition and the labour market. Surely, demographics and socioeconomic status could be critical factors in deepening gaps between different population groups. Therefore, it is imperative to clarify what determines inequality and the factors contributing to these changes.

\subsection{Participant (Subject) Characteristics}

\subsubsection{By Income Source}

Table 1 shows the contribution of each source of income to income inequality, as measured by the Gini coefficient. For the first period under review, earnings explain around three-fourths of the Gini coefficient. At the same time, taxes, transfers and other income account for the remaining quarter. The presented evidence indicates that social transfers and taxes can tame inequality through progressive social spending and taxes.

Earnings remained a huge contributor, explaining 71\% of the Gini coefficient between 2014 and 2018. This is because earnings are an important source of income (large factor share). Also, earnings are unequally distributed (high Gini coefficient within-earnings) and highly correlated with total income (households with higher income levels are more likely to earn more from work activities).

The decomposition exercise confirms that "other income" is highly unequally distributed, with a Gini hovering around 75.4. However, its contribution is overall small, reflecting the small share of this income component in total income.

Table 1. Contributions to Gini Coefficient, average

\begin{tabular}{lcccccc}
\hline & \multicolumn{3}{c}{ Contributions to Gini } & \multicolumn{3}{c}{ Elasticities of Gini } \\
\cline { 2 - 7 } & $\mathbf{2 0 0 5 - 2 0 0 9}$ & $\mathbf{2 0 1 0 - 2 0 1 3}$ & $\mathbf{2 0 1 4 - 2 0 1 8}$ & $\mathbf{2 0 0 5 - 2 0 0 9}$ & $\mathbf{2 0 1 0 - 2 0 1 3}$ & $\mathbf{2 0 1 4 - 2 0 1 8}$ \\
\hline Earnings & 37.2 & 37.2 & 39.0 & .41 & .41 & .43 \\
Other Income & 1.8 & 1.4 & 2.1 & .01 & .01 & .02 \\
Transfers & -2.2 & -1.3 & -2.8 & -.27 & -.27 & -.31 \\
Taxes & -9.6 & -9.4 & -10.1 & -.14 & -.14 & -.15 \\
Gini & 27.3 & 27.8 & 28.3 & & & \\
\hline
\end{tabular}

Table 2. Absolute change in the Gini coefficient between waves and its decomposition

\begin{tabular}{|c|c|c|c|c|}
\hline & & 2005-2009 & 2010-2013 & 2014-2018 \\
\hline \multirow{5}{*}{$\begin{array}{l}\text { Change in } \\
\text { factor share }\end{array}$} & Earnings & -1.6 & 0.0 & 0.2 \\
\hline & Other Income & 0.1 & 0.0 & 0.1 \\
\hline & Transfers & -0.2 & -0.8 & 1.1 \\
\hline & Taxes & 0.9 & -0.4 & 0.0 \\
\hline & Total Share & -0.8 & -1.2 & 1.4 \\
\hline \multirow{6}{*}{$\begin{array}{l}\text { Change in inequality } \\
\text { within each group }\end{array}$} & Earnings & 1.2 & 1.9 & 0.0 \\
\hline & Other Income & -0.7 & 0.3 & 0.5 \\
\hline & Transfers & 0.9 & 0.1 & -1.5 \\
\hline & Taxes & -0.4 & -0.5 & 0.2 \\
\hline & Total Inequality & 1.0 & 1.8 & -0.8 \\
\hline & Total Change in Gini & 0.2 & 0.7 & 0.6 \\
\hline
\end{tabular}


Social transfers account for 5\% of total inequality. The positive factor contribution of transfers to inequality is that these transfers often mainly benefit a small proportion of the workforce that has an insecure job and low incomes (means-tested) or infrequent or low work history (non-contributory) and a growing elderly proportion of the population that rely on public pensions as their main source of income. Social transfers account for $20 \%$ of total income and are negatively correlated with total income. The negative correlation indicates that these transfers target households at the lower end of the income distribution. Social assistance programmes such as the in-work benefit and non-contributory pensions, are means-tested and help reduce inequality.

Lastly, the decomposition exercise confirms that direct taxes have substantial equalising effects. The correlation of direct taxes with total income is large and negative (-0.91), indicating substantial equalising effects (richer households pay more taxes). The Gini coefficient stands at an average of -52.0 , implying that more affluent households borne the largest share of taxes to total income. Interestingly, compared to 2013, the Gini declined by 2.4 points. As a result, direct taxes have a lower redistributive element owing to the fact that between 2013 and 2015, the Government increased the income tax thresholds which were kept unrevised since then.

Looking at the marginal contributions for each income source, i.e., elasticities of Gini, we find that inequality is most responsive to changes in earnings and social transfers. For example, between 2014 and 2018, a $1 \%$ increase in earnings was associated with a $0.43 \%$ increase in the Gini coefficient. Similarly, a $1 \%$ increase in transfers brought about a $0.31 \%$ decline in the Gini coefficient. The marginal effects also verify that direct taxes have an equalising effect on the distribution.

Changes in the contribution rates of each income source are also interesting. The change in Gini is decomposed into two factors: the change in inequality within each income source and the change in the share of the different source. Table 2 shows how these two components fared for each source between 2005 and 2018. In the first period, the change in shares of the income components contributed to a decrease in total inequality. This is notably mirroring the smaller share in earnings. By contrast, the "change in inequality" factor contributed to an increased inequality, mostly driven by higher inequality within earnings.

The 2010-2013 period coincides with the onset and aftermath of the financial and economic crisis of 2009. Like in other downturns, blue-collar workers tend to be hit hardest in a recession than better paid white-collar workers. Indeed, the manufacturing industry was hit hardest by the crisis compared to financial services. Workers in the manufacturing industry either lost their job or resorted to reduced-hours arrangements. In contrast, job creation in financial services was little affected (Vella, 2018). Consequently, the Gini coefficient increased primarily because of higher inequality within-earnings whilst direct taxes, to some extent, mitigated this increase. The change in inequality within-transfers contributed to higher Gini, though marginally. Furthermore, the change in shares of the income components contributed to a decrease in total inequality. However, it did not offset the overall increase in purely inequality factors.

The higher inequality factor for social transfers in the first two periods needs to be taken in the context of structural fiscal efforts taken by the authorities after Malta's adherence to the euro area. These periods were characterised by fiscal consolidation to meet the Maastricht criteria and, as per the Council recommendations in 2011, to end the excessive deficit procedure through declines in the general Government expenditure ratio. However, this was outweighed by two-times revisions in the income tax bracket that had strengthened the redistributive power of taxes.

By contrast, the 2014-2018 period saw a major change in trends. The change in the allocation of the different components contributed to higher inequality. In contrast, the change in inequality within components contributed to lower inequality. The strongest contributors to inequality were transfers. During this period, transfers constituted a lower share of households' total income while inequality within transfers shrank. This reflects the 'making work pay' strategy initiated by the Government. While ensuring that the social security system guarantees the necessary level of social protection, it minimises the dependency effect by encouraging opportunities rather than dependencies.

Another notable development was the upward contribution of taxes to inequality. This reflects the widening of the tax bands for the middle- to upper-income class between 2006 and 2008, and 2013 and 2015, reducing some redistributive power.

\subsubsection{By Population Subgroup}

Various demographic and socioeconomic factors contribute to income inequality. Following Brewer et al. (2009), we identify and test several factors that potentially influence income inequality (see Note 1). The importance of these factors to inequality is defined as a ratio of between-effect inequality to overall inequality. The results are 
presented in Table 3.

Table 3. The ratio of inequality between subgroups to overall inequality GE(0), \%

\begin{tabular}{lccc}
\hline & $\mathbf{2 0 0 5 - 2 0 0 9}$ & $\mathbf{2 0 1 0 - 2 0 1 3}$ & $\mathbf{2 0 1 4 - 2 0 1 8}$ \\
\hline Household Disposable Income (Household level) & & & 24.6 \\
$\quad$ Education of Head of Household & 14.6 & 17.5 & 22.3 \\
Household Employment Structure & 30.5 & 21.0 & 17.8 \\
Employment Status of Head of Household & 12.5 & 13.3 & 8.9 \\
Household Family Structure & 13.8 & 11.7 & 5.5 \\
Age of Head of Household & 6.1 & 5.2 & 4.7 \\
Household Tenure & 2.2 & 2.6 & 20.4 \\
Earnings (Individual level) & & 15.3 & 14.0 \\
Occupation & 18.6 & 11.8 & 13.7 \\
Age & 8.7 & 15.5 & 10.7 \\
Full-Time/Part-Time & 15.1 & 7.9 & 3.5 \\
Education & 8.6 & 3.9 & 2.8 \\
Sex & 5.3 & 3.3 & 0.0 \\
Household Family Structure & 5.0 & 0.0 & \\
Citizenship & 0.1 & & \\
\hline
\end{tabular}

Table 4. Decomposition of income inequality by education of the head of household, average

\begin{tabular}{lcccc}
\hline & \% of population & \% of mean income & GE(0) & Gini \\
\hline Primary education or less & & & & \\
$2005-2009$ & 18.7 & 76.58 & 0.11 & 24.4 \\
$2010-2013$ & 14.6 & 75.35 & 0.11 & 23.0 \\
$2014-2018$ & 11.9 & 66.38 & 0.08 & 21.0 \\
Secondary education & & & & \\
$2005-2009$ & 63.6 & 95.44 & 0.12 & 25.4 \\
$2010-2013$ & 60.7 & 90.73 & 0.12 & 25.5 \\
$2014-2018$ & 56.7 & 86.99 & 0.11 & 25.0 \\
Post-secondary non-tertiary education & & & & \\
$2005-2009$ & 3.3 & 117.36 & 0.08 & 21.3 \\
$2010-2013$ & 5.7 & 113.80 & 0.09 & 22.3 \\
$2014-2018$ & 6.5 & 105.49 & 0.10 & 23.8 \\
Tertiary education & & & & 24.1 \\
$2005-2009$ & 14.4 & 146.91 & 0.11 & 24.0 \\
$2010-2013$ & 18.9 & 144.22 & 0.10 \\
\hline
\end{tabular}

Note. Income is Household Equivalised Disposable Income.

According to the results, between 2014 and 2018, the head of household education explained $25 \%$ of the variation in inequality of equivalised income. This is followed by household employment structure (22\%) and head of household employment status (18\%). Meanwhile, occupation status explained $20 \%$ of the total variation in earnings inequality, followed by age (14\%), work status (14\%) and highest educational level obtained (11\%). The rest of the variables have only marginal importance. Next, the first three variables at household level at the first variable at the individual level will be analysed in more detail (Note 2, 3).

\subsubsection{Education of Head of Household}

Education of the head of household is the most important factor that explains variation in inequality, and its importance has increased gradually over time. Table 4 confirms that education characterises the human capital, which reflects individual abilities and skills. Our workings confirm that head of households with higher levels of education have better returns.

Furthermore, the relative household income for head of households with primary, secondary and uppersecondary education has been falling behind. For example, during 2005-2009, a family with a head of household having a 
primary level of education or less earned $77 \%$ of the average income. 10 years later, this fell to $66 \%$. Mean income has been racing away because the increase in the share of head of household with tertiary educa-tion has pulled up the overall mean and consequently left some cohorts behind.

Moreover, there have been gradual and persistent population change effects towards more unequal groups than others. The population shift from primary to tertiary education spurred inequality pressures simply because the latter is structurally more unequal than the former.

\subsubsection{Household Employment Structure}

The number of multi-earner households has been steadily increasing over the past few decades. Table 5 shows that multi-earner households make up almost $60 \%$ of the population. In 2005, individuals living in multi-earner households amounted to $46 \%$ of the population, a sizeable 11 percentage points increase. This came against a drop of similar magnitude for single-earner households containing two or more adults. Households with more than one income have become commonplace in Malta and are generally considered more financially secure than households with one source of income. Much of the transition away from predominantly single-income households is attributed to evolving perspectives about the role of each partner in the household. This is accompanied by tendencies of Maltese youngsters to live in their parental home until their 30s and a significant rise in the number of women engaged in external employment either part-time or full-time. There was also a modest increase in single-earner households containing one adult and one-or-more-earner households with a head of household aged 65 or over during the period under review. These changes primarily reflect the narrowing gap in participation rates of men and women, the demographic shift in Malta's ageing population and the stronger attachment of older workers to the labour market.

One may argue that multi-earner households are at an advantage compared to single-earner households. One could argue that extra earnings should equate with augmented purchasing power, more consumer choice, economies of scale, and increased leisure time. Nevertheless, besides inflationary pressures in the product markets, including rising housing costs, a mature labour market with dual-earner families can also result in relatively flat wage trends due to increased labour supply if demand for labour has not experienced a similarly positively sized effect. Indeed, one can argue that increased participation of once-upon-a-time homemakers in the labour market "has had a paradoxical effect of making families less secure, less flexible and poorer" (Warren and Tyagi, 2003). When adjusting income for households' size and age composition and expressing it as a proportion of mean income, there is convergence towards mean income, apart from some few household types and years. It is hard to say what has caused multi-earner households to have less relatively equivalised income than before, considering that other factors interact with the earning structure of households, such as age and socioeconomic status of workers.

Meanwhile, the magnitude of inequality during this period increased too. Probably this phenomenon can be explained by the homogamy of spouses and partners. During this transition from single to dual or multi-earner households, this characteristic is thought to intensify income inequality by combining two high-income earners or two low-income earners into one group.

\subsubsection{Employment Status of Head of Household}

The distribution of the population by employment status of head of household partly echoes the buoyant labour market and changes in demographics due to the ageing population throughout the years. Individuals living in households with a full-time worker and having retiree as head of household have collectively increased by more than 4 percentage points. At first glance, this does not look substantial. However, at times these two forces could have counteracted each other out. 
Table 5. Decomposition of income inequality by earning structure of household, average

\begin{tabular}{|c|c|c|c|c|}
\hline & \% of population & $\%$ of mean income & GE(0) & Gini \\
\hline \multicolumn{5}{|c|}{ zero-earner households containing one adult } \\
\hline 2005-2009 & 1.6 & 57.4 & 0.17 & 23.0 \\
\hline $2010-2013$ & 1.6 & 55.0 & 0.25 & 26.0 \\
\hline 2014-2018 & 1.5 & 53.9 & 0.11 & 18.8 \\
\hline \multicolumn{5}{|c|}{ zero-earner households containing two or more adults } \\
\hline 2005-2009 & 6.4 & 50.2 & 0.15 & 25.8 \\
\hline 2010-2013 & 4.6 & 53.0 & 0.13 & 23.6 \\
\hline 2014-2018 & 3.6 & 48.0 & 0.11 & 22.7 \\
\hline \multicolumn{5}{|c|}{ zero-earner households with a head of household aged 65 or over } \\
\hline 2005-2009 & 11.0 & 68.1 & 0.12 & 22.8 \\
\hline $2010-2013$ & 11.4 & 70.9 & 0.10 & 21.7 \\
\hline 2014-2018 & 13.5 & 69.0 & 0.08 & 21.1 \\
\hline \multicolumn{5}{|c|}{ single-earner households containing one adult } \\
\hline $2005-2009$ & 2.3 & 106.7 & 0.11 & 24.9 \\
\hline $2010-2013$ & 3.3 & 111.2 & 0.13 & 27.6 \\
\hline 2014-2018 & 4.8 & 104.5 & 0.13 & 27.4 \\
\hline \multicolumn{5}{|c|}{ single-earner households containing two or more adults } \\
\hline $2005-2009$ & 32.4 & 84.2 & 0.09 & 23.3 \\
\hline $2010-2013$ & 26.4 & 84.2 & 0.11 & 25.5 \\
\hline 2014-2018 & 18.1 & 80.8 & 0.12 & 27.0 \\
\hline \multicolumn{5}{|c|}{ multi-earner households containing two adults } \\
\hline 2005-2009 & 30.3 & 122.8 & 0.08 & 22.1 \\
\hline $2010-2013$ & 33.2 & 117.5 & 0.10 & 24.5 \\
\hline 2014-2018 & 35.7 & 115.9 & 0.11 & 25.1 \\
\hline \multicolumn{5}{|c|}{ multi-earner households containing three adults or more } \\
\hline $2005-2009$ & 15.3 & 134.4 & 0.06 & 18.8 \\
\hline $2010-2013$ & 17.7 & 122.5 & 0.08 & 22.1 \\
\hline 2014-2018 & 20.8 & 118.8 & 0.09 & 22.9 \\
\hline \multicolumn{5}{|c|}{ one-or-more-earner households with a head of household aged 65 or over } \\
\hline 2005-2009 & 0.6 & 141.8 & 0.16 & 30.5 \\
\hline $2010-2013$ & 1.7 & 113.6 & 0.19 & 33.9 \\
\hline 2014-2018 & 1.9 & 127.0 & 0.20 & 34.1 \\
\hline
\end{tabular}

Note. Income is Household Equivalised Disposable Income.

Table 6. Decomposition of income inequality by employment status of the head of household, average

\begin{tabular}{|c|c|c|c|c|}
\hline & \% of population & \% of mean income & GE(0) & Gini \\
\hline \multicolumn{5}{|c|}{ Employee working full-time } \\
\hline $2005-2009$ & 62.3 & 111.1 & 0.10 & 24.3 \\
\hline $2010-2013$ & 63.8 & 111.3 & 0.10 & 24.4 \\
\hline 2014-2018 & 65.6 & 112.1 & 0.10 & 25.2 \\
\hline \multicolumn{5}{|c|}{ Employee working part-time } \\
\hline $2005-2009$ & 1.3 & 74.4 & 0.10 & 24.1 \\
\hline $2010-2013$ & 2.0 & 75.9 & 0.13 & 27.4 \\
\hline 2014-2018 & 1.8 & 78.4 & 0.13 & 27.2 \\
\hline \multicolumn{5}{|c|}{ Self-employed } \\
\hline $2005-2009$ & 12.7 & 101.2 & 0.12 & 27.2 \\
\hline $2010-2013$ & 11.0 & 100.1 & 0.17 & 30.8 \\
\hline 2014-2018 & 9.9 & 99.8 & 0.16 & 31.3 \\
\hline \multicolumn{5}{|c|}{ Unemployed } \\
\hline $2005-2009$ & 3.2 & 73.2 & 0.13 & 28.0 \\
\hline $2010-2013$ & 2.5 & 57.6 & 0.19 & 29.2 \\
\hline 2014-2018 & 1.7 & 46.4 & 0.11 & 21.5 \\
\hline \multicolumn{5}{|c|}{ Inactive above retirement age } \\
\hline 2005-2009 & 15.0 & 71.9 & 0.11 & 24.1 \\
\hline $2010-2013$ & 14.6 & 75.5 & 0.13 & 24.6 \\
\hline 2014-2018 & 16.1 & 71.7 & 0.09 & 22.9 \\
\hline \multicolumn{5}{|c|}{ Inactive below retirement age } \\
\hline $2005-2009$ & 5.5 & 70.0 & 0.25 & 36.4 \\
\hline $2010-2013$ & 6.2 & 65.6 & 0.17 & 29.1 \\
\hline 2014-2018 & 4.8 & 56.0 & 0.13 & 25.4 \\
\hline
\end{tabular}

Note. Income is Household Equivalised Disposable Income. 
The decomposition exercise demonstrates that labour status and work intensity are key determinants of income. Table 6 shows that households headed by a full-time worker are endowed with higher income than those headed by retirees. However, whilst the income of households headed by pensioners had their relative income relatively unchanged at $71 \%$ of average income, inactive persons below retirement age fell behind. This happened in a context where the number of people aged 0-59 living in households with very low work intensity has almost halved between 2005 and 2018. This may have helped to hold back inequality growth, but in the process, those who stayed inactive had their relative earnings reduced. Assessing whether higher income growth slows up inequality growth has proved to be challenging. On the one hand, the widening gap between employees and inactive persons can be seen as arising from rewards to work. By contrast, whether low-work intensity households did not participate in the labour market because of inequality of opportunities, such as less productivity, financial exclusion, or slower human capital accumulation is something which must be explored further.

Between 2010 and 2013, rising income inequality amongst most groups, save for inactive persons below retirement age, has contributed to notable within-group inequality. In the following period, the fall in the relative incomes of unemployed and inactive groups exerted upward pressures on inequality. However, this pressure was mitigated by a higher proportion of people living with a full-time head of household as full-time workers have higher mean earnings than other groups.

Table 7. Decomposition of earnings inequality by occupation, average

\begin{tabular}{|c|c|c|c|c|}
\hline & $\%$ of population & $\%$ of mean income & GE(0) & Gini \\
\hline \multicolumn{5}{|c|}{ Elementary occupations } \\
\hline $2005-2009$ & 11.6 & 73.9 & 0.16 & 27.1 \\
\hline $2010-2013$ & 9.4 & 69.2 & 0.32 & 34.5 \\
\hline 2014-2018 & 7.7 & 61.5 & 0.24 & 31.2 \\
\hline \multicolumn{5}{|c|}{ Plant and machine operators and assemblers } \\
\hline $2005-2009$ & 22.8 & 89.2 & 0.11 & 22.8 \\
\hline $2010-2013$ & 19.8 & 84.9 & 0.21 & 28.3 \\
\hline 2014-2018 & 16.6 & 81.0 & 0.19 & 28.0 \\
\hline \multicolumn{5}{|c|}{ Skilled agricultural and fishery workers } \\
\hline $2005-2009$ & 1.6 & 95.0 & 0.16 & 26.7 \\
\hline $2010-2013$ & 1.6 & 83.8 & 0.34 & 32.9 \\
\hline 2014-2018 & 1.1 & 83.8 & 0.24 & 33.9 \\
\hline \multicolumn{5}{|c|}{ Service workers and shop and market sales workers } \\
\hline $2005-2009$ & 16.1 & 77.2 & 0.21 & 29.9 \\
\hline $2010-2013$ & 18.4 & 71.8 & 0.33 & 35.0 \\
\hline 2014-2018 & 19.3 & 69.0 & 0.26 & 32.1 \\
\hline \multicolumn{5}{|l|}{ Clerks } \\
\hline $2005-2009$ & 12.4 & 85.8 & 0.13 & 23.3 \\
\hline $2010-2013$ & 12.1 & 81.5 & 0.20 & 26.4 \\
\hline 2014-2018 & 11.7 & 77.0 & 0.19 & 26.7 \\
\hline \multicolumn{5}{|c|}{ Technicians and associate professionals } \\
\hline $2005-2009$ & 13.9 & 107.2 & 0.12 & 23.4 \\
\hline $2010-2013$ & 14.1 & 112.2 & 0.20 & 28.2 \\
\hline 2014-2018 & 13.9 & 104.6 & 0.21 & 28.9 \\
\hline \multicolumn{5}{|l|}{ Professionals } \\
\hline 2005-2009 & 13.1 & 132.3 & 0.13 & 24.8 \\
\hline $2010-2013$ & 14.6 & 129.1 & 0.23 & 28.5 \\
\hline 2014-2018 & 18.3 & 130.0 & 0.21 & 29.1 \\
\hline \multicolumn{5}{|c|}{ Legislators, senior officials and managers } \\
\hline $2005-2009$ & 8.5 & 169.0 & 0.17 & 29.5 \\
\hline $2010-2013$ & 10.1 & 175.2 & 0.25 & 33.3 \\
\hline 2014-2018 & 11.4 & 177.9 & 0.27 & 35.4 \\
\hline
\end{tabular}

Note. Income is Earnings at the individual level. 


\subsubsection{Individual's Occupation}

The shift towards a service-oriented economy has increased the demand for service workers and professionals, affecting earnings inequality. Here, we decompose earnings at the individual level to classify unemployed and inactive as an occupation at the house-hold level.

Table 7 illustrates the occupational structural changes. Gradual declines in occupations at the lower end of the skill distribution are observed. For instance, notable declines are recorded in elementary occupations from $12 \%$ to $8 \%$, usually requiring limited education and training - and the increasing share of service, managerial and professional workers. On the other hand, the share of clerks and technicians remained relatively stable at $12 \%$ in the past 14 years.

Throughout the study period, relative wages of unskilled and semi-skilled workers declined gradually. For example, whereas the relative income of elementary occupations declined from $74 \%$ to $62 \%$, the relative income of senior workers strengthened further to almost twice as much as the average income. The gap in relative wages can be linked to productivity and the training and human capital content of the tasks performed. The recession of 2009 saw a significant increase in earnings inequality between different occupations. This increase was partially reversed in the subsequent period for low and medium skill level jobs. Overall, there have been wider discrepancies between low and high skilled jobs. However, when considering the effect of factor share changes, they become less significant in magnitude.

\section{Conclusion}

This paper demonstrates that an income inequality indicator on its own hides the complexity of its interpretation and explanation. The theoretical discussion led to identifying the major inequality indices highlighting that relying on one indicator oversimplifies the picture. We approach this discussion by analysing income generation; namely factor endowments, factor productivity and income redistribution. Specifically, our discussion identified several factors affecting income inequality, including the imperfectiveness of the labour market that can increase inequality, and on the other hand, the welfare system that limits or reduces it.

While the Gini coefficient remained relatively stable between 2005 and 2018, the generalised entropy indicators show modest increases when the inequality measure is specifically sensitive to the existence of large incomes. In the same vein, the Lorenz curve got further away from the line of equality at the upper end of the income distribution, showing modest inequality increases during this period.

Government policy through taxation and benefits have recognised that inequality is undesirable for society. Social transfers have proved to provide a greater safety net to citizens than it was 14 years ago. On the other hand, reducing the marginal tax rates for middle- and upper-income groups has put a strain on the redistributive power of taxes on income. More recently, the debate has been gradually concentrating on the gradual shift from direct to indirect taxes. While indirect taxes are less distortionary, they are not redistributive in nature: the poorer members of society have high marginal propensities to consume and therefore, indirect taxation accounts for a higher percentage of their income.

The study also finds that income inequality is mostly attributed to differences in the individual's qualifications, hours worked, occupations, and household employment structure and size. In general, this accords with the theoretical insights that the productivity of workers plays a significant role in the labour market. Without policy intervention, the imperfectness of the labour market can result in further inequality. Thus, an important implication for policy is to reduce further barriers to economic inclusion as the benefits of growth can easily become battered by its downsides, especially due to the roles of globalisation, technology and market forces.

Though this paper identifies a number of factors through bivariate between-within group analysis, it should also be pointed out that the mechanism in forming income inequality is too complex to be explained by only one factor such as education. Education may affect income inequality through other mediators, such as health, number of children in household and marriage matching. The impact of education on inequality can also work through other parental mechanisms, such as parents' nutrition and parental investment into children. For example, parents' nutrition will affect children's health and children's health will further affect their educational achievement and labour productivity.

Summing up, income inequality is an important aspect of economic development. Besides unfairness, excessive inequality reflects wastefulness of resources. Inequality lowers mobility because it shapes opportunities. It exacerbates the differences between individuals, distorts market signals and incentives, and shifts the balance of power away from the less affluent members of society. If we are concerned about equality of opportunity, we should also be concerned about equality of income. Thus, mitigating the risks and consequences of inequality 
gives valuable insights for thriving our society's overall economic and social development objectives.

\section{Acknowledgments}

Funding: This research was funded by the Centre for Labour Studies within the University of Malta.

Data Availability Statement: The present document has been produced using the EU-SILC 2005-2018 Data National Statistics Office Malta. The calculations and conclusions with the doc-ument are the intellectual product of the present authors. The data that support the findings of this study are available from the National Statistics Office Malta. Restrictions apply to the availability of these data, which were used under license for this study.

Conflicts of Interest: The authors declare no conflict of interest. The funders had no role in the design of the study; in the collection, analyses, or interpretation of data; in the writing of the manuscript, or in the decision to publish the results.

The authors would like to thank the former Centre for Labour Studies Director Dr Anna Borg, current Director Dr Luke Fiorini and staff member Dr Manwel Debono for their review and support.

\section{References}

Atkinson, A. B. (1970a). On the Measurement of Inequality. Journal of Economic Theory, 2. https://doi.org/10.1016/0022-0531(70)90039-6

Baldacchino, G. (1993). L-akbar Unjon? Aspetti Socjjoligicici. In E. Zammit (Ed.), Trejd Unjoniżmu f'Malta: Harsa Lura u 'l Quddiem (pp. 9-13). Malta: University of Malta.

Baldacchino, G. (2010). Industrial Relations in Malta: Revised Edition. Hal Luqa: Miller Distributions Ltd.

Baldacchino, G., \& Gatt, R. (2009). Thirteen Years Later: Trade Unions in the Maltese Private Sector Revisited. Bank of Valletta Review, 40(2).

Brewer, M., Muriel, A., \& Wren-Lewis, L. (2009). Accounting for Changes in Inequality since 1968: Decomposition Analyses for Great Britain. Institute for Fiscal Studies Report for the National Equality Panel.

Checchi, D., Ichino, A., \& Rustichini, A. (1999). More Equal but Less Mobile?: Education Financing and Intergenerational Mobility in Italy and in the US. Journal of Public Economics, 74(3), 351-393. https://doi.org/10.1016/S0047-2727(99)00040-7

Costa, R. N., \& Pérez-Duarte, S. (2019). Not all Inequality Measures were Created Equal - The Measurement of Wealth Inequality, its Decompositions, and an Application to European Household Wealth. European Central Bank, No. 31. https://doi.org/10.2866/957288

Cowell, F. A. (2000). Measurement of Inequality. Handbook of Income Distribution, 1, 87-166. https://doi.org/10.1016/S1574-0056(00)80005-6

Cowell, F. A., \& Kuga, K. (1981). Inequality Measurement: An Axiomatic Approach. European Economic Review, 15(3), 287-305. https://doi.org/10.1016/S0014-2921(81)80003-7

Gini, C. (1912). Variabilità e mutabilità. Bologna.

Dalton, H. (1920). The Measurement of the Inequality of Incomes. Economic Journal, 30. https://doi.org/10.2307/2223525

Dasgupta, P., Sen, A. K., \& Starrett, D. (1973). Notes on the Measurement of Inequality. Journal of Economic Theory, 6. https://doi.org/10.1016/0022-0531(73)90033-1

Davies, J. B., \& Hoy, M. (1995). Making Inequality Comparisons when Lorenz Curves Intersect. American Economic Review, 85, 980-6.

Foster, J. E. (1985). Inequality Measurement. In H. P. Young (Ed.), Fair Allocation, Proceedings of Symposia in Applied Mathematics, 33. Providence, RI: American Mathematical Society. https://doi.org/10.1090/psapm/033/814332

Goos, M., Manning, A., \& Salomons, A. (2014). Explaining Job Polarisation: Routine-Biased Technological Change and Offshoring. American Economic Review, 104(8), 2509-2526. https://doi.org/10.1257/aer.104.8.2509

Kollmeyer, C. (2013). Family Structure, Female Employment, and National Income Inequality: A Cross-National Study of 16 Western Countries. European Sociological Review, 29(4), 816-827. 
https://doi.org/10.1093/esr/jcs060

Ricci, U. (1916). L'indice di variabilita e la curve dei redditi. Rome.

Hey, J. D., \& Lambert, P. J. (1980). Relative Deprivation and the Gini Coefficient: Comment. The Quarterly Journal of Economics, 95(3), 567-573. https://doi.org/10.2307/1885094

Hendel, I., Shapiro, J., \& Willen, P. (2005). Educational Opportunity and Income Inequality. Journal of Public Economics, 89(5-6), 841-870. https://doi.org/10.1016/j.jpubeco.2004.11.004

Jenkins, \& Van Kerm. (2011). The Measurement of Economic Inequality. In B. Nolan, W. Salverda, \& T. M. Smeeding (Eds.), The Oxford Handbook of Economic Inequality. https://doi.org/10.1093/oxfordhb/9780199606061.013.0003

Jenkins, S. P. (1999a). Ineqfac: Stata Module to Calculate Inequality Decomposition by Factor Components. Statistical Software Components S366003, Boston College Department of Economics.

Jenkins, S. P. (1999b). Ineqdeco: Stata Module to Calculate Inequality Indices with Decomposition by Subgroup. Statistical Software Components S366002, Boston College Department of Economics.

Jenkins, S. P. (1995). Accounting for Inequality Trends: Decomposition Analyses for the UK, 1971-86. Economica, 62(245), 29-63. https://doi.org/10.2307/2554775

Jurkatis, S., \& Strehl, W. (2013). Dos and Don'ts of Gini Decompositions. Working Paper Series, No 2013-03. Berlin Doctoral Program in Economics and Management Science, November.

Lerman, R. I., \& Yitzhaki, S. (1985). Income Inequality Effects by Income Source: A New Approach and Applications to the United States. Review of Economics and Statistics, 67(1), 151-156. https://doi.org/10.2307/1928447

Lewis, J. (1992). Gender and the Development of Welfare Regimes. Journal of European Social Policy, 2, 159-173. https://doi.org/10.1177/095892879200200301

Mookherjee, D., \& Shorrocks, A. (1982). A Decomposition Analysis of the Trend in UK Income Inequality. The Economic Journal, 92(368), 886-902. https://doi.org/10.2307/2232673

Mouw, T., \& Kalleberg, A. L. (2010). Occupations and the Structure of Wage Inequality in the United States, 1980s to 2000s. American Sociological Review, 75(3), 402-431. https://doi.org/10.1177/0003122410363564

Newbery, D. M. G. (1970). A Theorem on the Measurement of Inequality. Journal of Economic Theory, 2. https://doi.org/10.1016/0022-0531(70)90039-6

Nolan, B., Richiardi, M. G., \& Valenzuela, L. (2019). The Drivers of Income Inequality in Rich Countries. Journal of Economic Surveys, 33(4), 1285-1324. https://doi.org/10.1111/joes.12328

Restuccia, D., \& Urrutia, C. (2004). Intergenerational Persistence of Earnings: The Role of Early and College Education. American Economic Review, 94(5), 1354-1378. https://doi.org/10.1257/0002828043052213

Schwartz, C. (2010). Earnings Inequality and the Changing Association between Spouses' Earnings. American Journal of Sociology, 115, 1524-1557. https://doi.org/10.1086/651373

Sen, A., \& Foster, J. E. (1997). On Economic Inequality. UK: Oxford University Press.

Shorrocks, A. F. (1982). Inequality Decomposition by Factor Components. Econometrica, 50, 193-212. https://doi.org/10.2307/1912537

Shorrocks, A. F. (1980). The Class of Additively Decomposable Inequality Measures. Econometrica: Journal of the Econometric Society, 48(3), 613-625. https://doi.org/10.2307/1913126

Shorrocks, A. F., \& Foster, J. E. (1987). Transfer Sensitive Inequality Measures. Review of Economic Studies, 54. https://doi.org/10.2307/2297571

Sheshinski, E. (1972). Relation between a Social Welfare Function and the Gini Index of Inequality. Journal of Economic Theory, 4. https://doi.org/10.1016/0022-0531(72)90167-6

Sylwester, K. (2002). Can Education Expenditures Reduce Income Inequality? Economics of Education Review, 21(1), 43-52. https://doi.org/10.1016/S0272-7757(00)00038-8

Van Kerm, P. (2020). SGINI: Stata module to compute Generalised Gini and Concentration coefficients, Gini correlations and fractional ranks.

Yang, J., \& Qiu, M. (2016). The Impact of Education on Income Inequality and Intergenerational Mobility. 
China Economic Review, 37, 110-125. https://doi.org/10.1016/j.chieco.2015.12.009

Yntema, D. B. (1933). Measures of the Inequality in the Personal Distribution of Wealth and Income. Journal of the American Statistical Association, 28. https://doi.org/10.2307/2278132

Vella, M., \& von Brockdorff, P. (2019). Pensions across Generations: Scenarios for the Maltese Islands. Journal of International and Comparative Social Policy. https://doi.org/10.1080/21699763.2019.1593878

Weeden, K. A., Kim, Y. M., Di Carlo, M., \& Grusky, D. B. (2007). Social Class and Earnings Inequality. American Behavioral Scientist, 50(5), 702-736. https://doi.org/10.1177/0002764206295015

Zammit, E. (1993). Trejd Unjoniżmu f'Malta: Harsa Lura u 'l Quddiem. University of Malta.

Semenak, S. (1995, December 28). Feeling right at home: Government residence eschews traditional rules. Montreal Gazette.

\section{Notes}

Note 1. A detailed description of the decomposition methods is produced in Appendix A.

Note 2. An important driver of inequality is the health condition and work intensity of household members. These were excluded from our analysis due to data limitations.

Note 3. Detail for the other variables will also be provided upon request.

\section{Appendix A}

\section{Decomposition by Income Source}

Household income comprises various sources, such as labour income, capital in-come, social transfers and taxes. Shorrocks (1982) provides an exact decomposition of in-come inequality into the various sources of income. By definition, each income is computed as the summation of income received from different sources, i.e.

$$
Y=\Sigma_{k} Y_{i}^{k}
$$

where $Y_{i}^{k}$ is the income individual i receives from income source $\mathrm{k}$.

There is a unique decomposition rule for which inequality in total income across ob-servations can be expressed as the sum of inequality contributions from each factor com-ponent (Shorrocks, 1982a). The proportionate contribution of source $\mathrm{k}$ to total inequality is:

$$
s_{k}(Y)=\frac{\operatorname{cov}\left(Y^{k}, Y\right)}{\sigma^{2}(Y)}
$$

$s_{k}(Y)$ is then the covariance of this factor with total income, scaled by the total income variance. Equivalently, $s_{k}$ is the slope coefficient from the regression of source $k$ on total income.

The sum of shares is one, and each share represents the weight that each income source explains to inequality. Shorrocks proves that the decomposition is not dependent on which inequality measure is used. However, the advantage of using half the squared coefficient of variation over other inequality measures is that total inequality can be expressed in terms of the factor correlations with total income, the factor shares in total income, and the factor inequalities (Jenkins, 1999a).

In this study, we opted to decompose the Gini coefficient similarly due to its widespread use. Specifically, we use Lerman and Yitzhaki (1985) and Van Kerm (2020) methods by writing the Gini coefficient as

$$
\begin{gathered}
G=\sum_{k=1}^{K} \frac{\operatorname{cov}\left(y_{k}, F\right)}{\operatorname{cov}\left(y_{k}, F_{k}\right)} \times \frac{2 \operatorname{cov}\left(y_{k}, F\right)}{\bar{y}_{k}} \times \frac{y_{k}}{y} \\
G=\sum_{k=1}^{K} R_{k} G_{k} S_{k}
\end{gathered}
$$

where $F$ is the cumulative distribution of income. Therefore, the overall Gini coefficient can be interpreted as the product of the following three factors: $R_{k}$ is the "Gini correlation" measuring how the income source and the distribution of total income are correlated, $G_{k}$ is the "Gini coefficient" how equally or unequally distributed the income source is, and $S_{k}$ is the income share measuring how important the income source is to total income.

Lerman and Yitzhaki (1985) also derive the elasticity of the Gini coefficient, which measures the percentage 
change in the Gini coefficient brought about by a percentage change in mean income of source $k$. Indeed, the partial derivate of (A1) is

$$
\frac{\partial G}{\partial e_{k}}=S_{k}\left(R_{k} G_{k}-G\right)
$$

The sum of all relative marginal effects is zero, meaning that changing all income sources by the same marginal amount leaves the Gini unchanged. Furthermore, dividing (b) by the overall Gini Coefficient yields the source's marginal effect relative to the overall Gini. By definition, the sum of the elasticities of all sources is null because an increase of all income components by $1 \%$ leaves inequality unchanged overall.

Given that Equation (A1) is expressing the Gini coefficient as a product of factor share $\left(S_{k}\right)$, the correlation of income source to total income $\left(R_{k}\right)$, and the respective Gini for each source $\left(G_{k}\right)$, the change in Gini must be sourced from these three components. Specifically, a change in the Gini coefficient can be attributed to a change in factor share (the importance of the income source with respect to total income), substantial inequality within earnings (how equally or unequally distributed the income source is) and a high correlation between other sources of income (the extent and direction of the correlation of the income source with total income). Similar to Podder and Chatterjee (2002), changes in the Gini coefficient can be estimated by differentiating Equation (A1) with respect to time. See Jurkatis and Strehl (2013) and Costa and Pérez-Duarte (2019) for alternative interpretations.

$$
\Delta G_{t}=\underbrace{\sum_{r} \frac{C_{k, t}+C_{k, t-1}}{2} \Delta S_{k, t}}_{\text {Change in share }}+\underbrace{\sum_{r} \frac{S_{k, t}+S_{k, t-1}}{2} \Delta C_{k, t}}_{\text {Change in inequality }}
$$

In Equation (A3), $C_{k}$ is the concentration coefficient, measured as the multiplication of $G_{k}$ and $S_{k}$. $C_{k}$ is also referred to as the 'pseudo Gini' associated with income source $k$. A value less than zero indicates that the factor contributes to lowering inequality, whereas a value greater than zero means that income source has contributed to more inequality.

\section{Decomposition by population subgroup}

The inequality index can be decomposed into various population subgroups. In particular, total inequality can be expressed as the sum of inequalities within each group and between groups. On the one hand, inequality within groups is the weighted sum of ine-qualities within each subgroup. On the other hand, between-group inequality is the inequality that would arise were each person receives the mean income of the subgroup to which each household belonged.

Mookherjee and Shorrocks (1982) and Jenkins (1995), taking advantage of the addi-tive decomposability of the mean $\log$ deviation (MLD), show that changes in inequality can be decomposed into between and within components, i.e.

$$
\mathrm{GE}(0)=\underbrace{\Sigma_{g} v_{g} G E(0)_{g}}_{\text {Within }}+\underbrace{\sum_{g} v_{g} \ln \left(1 / \lambda_{g}\right)}_{\text {Between }}
$$

where $\lambda_{g}=\mu_{g} / \mu$ and $v_{g}=n_{g} / n$, with $\mu_{g}$ the mean income/earnings of subgroup $g$ and $n_{g}$ its size, and with $\mu$ and $n$ the mean and size of the whole population (Jenkins, 1999b). The first term of Equation (A4) captures inequality within subgroups, whilst the second term represents inequality originating from differences in the mean income of subgroups.

\section{Copyrights}

Copyright for this article is retained by the author(s), with first publication rights granted to the journal.

This is an open-access article distributed under the terms and conditions of the Creative Commons Attribution license (http://creativecommons.org/licenses/by/4.0/). 